\title{
The Book Market Influence Of Book Integrated Design
}

\author{
Jing Zhang ${ }^{1}$ \\ ${ }^{1}$ Guangxi Technological College of Machinery and Electricity, China
}

Keywords: Integrated design books, Book sales, Book market, Influence

\begin{abstract}
By understanding books connotation analysis of the development of book integrated design, the understanding of books is no longer just in order to meet its usefulness, but began to pay more attention to their aesthetic needs. Understand consumer needs and buying psychology on the basis of its use into the book design and acting on the book market, which is from the point of view of consumers to buy psychological Book Integrated design in the book market sales. On this basis, product sales, for example, by demonstrating the book integrated design is more beautiful, the higher the sales ", book design into the impact of the market economy of the national standard of living it into people with a strong attitude vision, to promote sales of the book market.
\end{abstract}

\section{Introduction}

Production technology of the rapid development of science and technology changes with each passing day, also appeared in the field of books in an unprecedented development, appeared a variety of text vector, and traditional book slowly out of our life, the book sales market is declining, while at the same time, the book sellers in order to improve the situation, should the aesthetic needs of customers, to vigorously develop book design, in the books in the process of production materials and technology, thought and art, features and constituent elements such as the content, the local and integrated the more humanized and more accord with people's personalized aesthetic demand change [1]. And the development of book binding, the book sales market boom again.

In humans, in ancient times, there is a simple packaging, such as packages of food, cane bound objects, etc., with leaves it out just for the purpose of practical, the objects don't think the packing is beautiful [1]. Cultural heritage development, the original culture, people just left for future generations a better to live in simple symbols, and carry items of these symbols are a stone, wall, animal bones and so on something hard, this writing can only be known as the fundamental, and there is no packaging, it's just for the sake of easy to save, does not pay attention to the other, and with the development of human civilization, there is more fundamental, and the vehicle more delicate and cabinet, to this day, people about the packaging, more is to take its metaphorical meaning [1]. Actually packing is as early as 700 years ago as a sales tool in use. Again after more than half a century of development, along with the social economy developed, packaging industry also increasingly prosperous, until now the enterprise "not packaging, not survival" the point of "no packaging, no success".

\section{The integrated design of books}

The connotation of the books. Books are a great symbol of human civilization, is a tool for human knowledge, accumulate the dissemination of culture, the information capacity big, easy to flow and humanity, it is shouldering the excellent scientific culture heritage; accelerate the diffusion of information and knowledge. Historically, books, art form evolution constantly change which evolution always inseparable from the history and economic condition, form of books, has its unique time imprinting. The development of our country's books is about two thousand seven hundred years of history [1]. With our knowledge growth, textbooks and extracurricular reading is after several thousand years of history is presented to us.

What is the integrated design books. Books integrated design is a book in the decoration design work in the process of production, books are the integrated design book materials in the production process and technology, art and the thought, content and appearance of the global and local combined 
into harmony, such as whole, the art of beauty. But books integrated design is the floorboard of the modeling design books [2]. Generally includes choosing the cover materials, paper, determine the design patterns, size, font size, font, decision binding, printing and production methods. Book design is a whole visual communication activities, it has two goals: one is to use some words and symbols to record the ideas of the author; the second is to communicate to others.

Under the market economy the integrated design of books. Today with the establishment of market economy, the rise of innovative products and technology, and in the fierce market competition, promote the development of all kinds of consumer products and, of course also inevitably promote the transformation of the integrated design concept of art books and updated, changed the books in the past "bouquet afraid of deep alley", "as long as the content don't skin" of the old ideas, the integrated design of books got high degree of artistic value.

Publisher is now under the drive of market economy, breaking the previous "Commons" operation mechanism, in the new era of new look presents a lot of carefully planned to build classic books on the bookshelf [2]. 21st century publishing house, relay press, China children press these dominant under the condition of market economy, they bookshelf before the shop is always packed with smart lovely child. It is very popular publishing industry also has a word: readers to buy a book, a look, look, and three content. Because the book market operation rules, has been to the integrated design exquisite beautiful books to give a special favor, for books integrated design commercial value given in the book market sales more fully [2]. Books integrated design art under the market economy depends on market demand, so it is very important to understand the consumer's psychology. If you don't know the market demand, integrated design books design is actually lost his own existence value.

\section{Consumers' purchasing psychology}

Customers to buy goods, on the surface, gang get the cash on delivery, is very simple. Customers to purchase goods, in fact, not only need to decide by consumers, but also influenced by other factors, from walked into the store to buy, there is a psychological activity process [3].The consumer purchasing psychology is complicated, the enterprise marketing based on the research of the consumers to buy, and master the regular pattern of its purchase behavior, so as to make effective marketing strategy, to achieve enterprise marketing goals. Book sales to consider the consumer's purchase psychology, so as to promote the sale of books, thus accelerating the flow of information and culture. In book sales, influence consumers to purchase are the books, the starting point of the psychological change of packaging design, book design. Well begun is half done, buy the psychological changes in product sales is crucial.

Publicity caused by impulse purchase. The vast majority of consumers are to buy the lack of relevant professional knowledge, knowledge and market knowledge, especially for some strong technical and complicated operation of goods, more a lack of knowledge. In most cases, when consumer is bought often is strongly influenced by emotions. Accordingly, consumer is vulnerable to advertising, product packaging, packaging and other promotions, the effect of impulse buying. And the factors influencing customers to buy impulse is the main commodity factor [3]. The basis of commodities is to meet customer needs, is the most important factors that influence the buying motives; Impulse buying behavior tend to occur in the customer involved in buying degree is low, low value, the convenience of frequent purchases. For convenience, the customers for its general performance, usage, characteristics are better than familiar with, and inexpensive, and necessary expenses, depends on personal preference; do not need to compare similar products. For the books, this spirit product, its appearance, packaging, advertising, sales promotion, price, point-of-sale plays an important role in the sales, such as impact of books appearance beauty, packing force of propaganda, as well as the impact on consumers' spiritual content randomness is bigger, impulse buying is very strong, also. And cause the impulse purchase, book design plays a vital role.

Era characteristics caused by the purchasing psychology changes. Consumers to buy is often guided by spirit of the age, social customs, customs, allowing people to the consumer to buy some new needs [4]. After the APEC meeting, Tang suit become the trend of The Times, with the popular. 
And as society's emphasis on knowledge increases, the demand of talents of making people's need for books, stationery. The characteristics of the Times show the consumer to buy. With the development of social economy, the aesthetic consciousness of the people, for the cultural products, people no longer just to absorb cultural knowledge, for the appearance of cultural products the demand is higher and higher. Buy cultural products do not only to need to buy more, more is because aesthetic consciousnesses too to meet again at the same time improve cultural knowledge and purchase [4]. This is especially true for books. In today's social and economic rapid development, people's life pressure is more and more big, the book as a relaxed body and mind, most of the time, improve their self-cultivation way, when consumers go out to the bookstore, delicate and beautiful and artistic, binding and fashion will first attract customer's attention, arouse people's purchasing psychology. And in the era of digital publishing, the development of culture more prosperous, more books in the form of electronic version appeared on the network platform, to a without design of electronic books page and carefully designed electronic books which can cause people to buy more.

\section{The role of books integrated design in book market sales}

The commercial tide of global market economy promotes, which has been as noble and pure elegant culture books, also changed in the surging tide elegant appearance. The power of the commercial tide, not only increases the integrated design of books the business status of art, and also make the popular trend of the whole design style of the book. Such changes in the market, all the books by different books integrated design have different sales.

The role of book design sold on the market. With material product homogeneity of nowadays society, something can attract more customers? DuPont's law has pointed out, and about 63\% of consumers are completely according to the packaging and the packaging of goods purchase decision, it is because of this, today's market economy has been called the "eyeball economy", the only cause the attention of consumer goods, is it possible to let consumers to buy products. So that the packing determines is whether consumers purchase of consumer behavior [5]. A seasoned vendors with a new look at the packing can be concluded that the early stage of the product market sales performance. Therefore, the enterprise need use packaging complete set of its own brand and product promotion. And the integral design of the book, press must be in fluctuation full time is in addition to the content design, attract readers' attention, and then opened the book, again good content, not open mind, and everything is in vain.

Today, in a variety of books, the fast pace of life for consumers to have no time to leisurely stroll the bookstore, and one by one, turn over every book to see the stand or fall of content. Consumers focus on every book time is very short, must seize the consumer's eyes swept the shelf for an instant. Only books, comprehensive utilization of the integrated design elements such as color, shape, material, at the same time show the connotation of the category of books, information, highlight the books with the demands of consumers and the aesthetic in common, form the visual impact, to consumer make strikingly books on the bookshelf, can effectively attract consumers.

Books bring economic benefits to the integrated design performance materials and technology. In recent years, with the rapid development of China's economic strength, people's aesthetic demand increasingly diverse, material culture and living standards have greatly improved, the demand for books integrated design is more and more high, and then only with Chinese traditional elements to design books can no longer satisfy the aesthetic needs of readers of books, and books, the design idea of the integrated design is produced very big change, this change on the requirement of printing process and material is more exquisite [5]. And precious materials used more and more, and even a few years ago books integrated design industry "hot" gold and silver. Now, with the improving of the binding process, printing process, the domestic "face book" in luxury and delicate achieves a considerable height. Squeeze film hot stamping, hardened leather and gold, made books annatto, made from PVC material book covers are variety, such as the design books insert excellent illustrations, etc., various styles of design never stopped. And seller is essential with exquisite books integrated design [6]. Look just like the cover of a good advertisement, can arouse the reader's purchase desire, let the reader has the determination to complete the purchase. Books, of course, the 
integrated design quality is different, it's in book sales market sales effect can make a big difference, the integral design of the beautiful can let there is added value books, books integrated design art itself can also become the selling point of the book market, so that the books in the market, get the best sales, that is to say, "books are the integrated design of the beauty, the higher the sales".

\section{Books sold on the market in the integrated design of different functions}

With the improvement of social civilization, the rapid development of market economy, the market competition is intense, the emergence of computer digital technology, plus advertising design, packaging design work in sales, and update the book designer ideas, books design aesthetic function and cultural taste are improved. Book design art value and the role of more and more get of people admitted that book design style and craft also emerge in endlessly, unusually brilliant [6]. And design idea, design means, design direction are also profound changes have been made under the condition of market economy; have a lot of new features.

Books also present different forms, and each form is more convenient to carry and read. That even in today's Internet age, the digital publication of a large number of book sales markets, of course, traditional books will still remain. And compared with the modern electronic products, high-quality goods, the classic, collection and transmission will be the important attributes and essential feature of the paper publications. Due to the digital publication of the market share, book binding design will also pay more attention to the design of digital publications.

Books integrated design with sales force and discrimination. Books integrated design is first show that the sales force, to attract consumers' main function. It has again discrimination [4]. The vendor in this story though success attracted consumers, but as long as don't product packaging, consumer is the packing without outstanding performance characteristics of the product, the product packaging is also failed. Now consumers are not choose the wrong thing, not tore books cover, left. Now books integrated design need to let consumers to see the integrated design, can fully understand the types and features of books. An integrated design can not only requirements of this book design beautiful, more can let books themselves will talk, books about the content and characteristics of fitting, books integrated design shown in front of consumers communication force size, a direct impact on a product in the market situation is good or bad.

Books are the integrated design is a kind of image force. Entered the era of brand consumption in the 21st century, and entered the personalized consumption era, consumers buy books not just in order to meet the requirements of material, and value can bring their goods more than meet the individuality and mental pleasure, it depends on the integrated design on the senses to show it. Integrated design as a brand of the external performance is the press wanted his image to consumers a kind of what feeling. It generated by the differences, and hence the show "brand characteristics", make it become the dominant factor to attract consumers [7]. Integrated design aesthetic satisfaction and mental interest is what consumers buy, on the whole design on behalf of the brand in the mind to form a brand, and fully show the connotation of the brand. If connotation or no is not prominent, the consumer to hear it and see packaging that do not produce a Lenovo would make the brand become madras reflected.

Books integrated design is a kind of cultural power. Books are the core of the integrated design is not just reflect on the appearance of the image, it is important to show the affinity of books and the harmonious combination between personality, the book of the cultural connotations carried by the effective display [7]. Product packaging of mineral water, for example, in the sales, because on the palate is very difficult, every manufacturer is using packaging cause consumers, including those colorful fashionable appearance of bottled mineral water for the love of consumers, and individual manufacturer new portable display function, with its convenient drinking and unique waist matching function get a stable consumer group identification. Product packaging is interpretation of "who cater to consumer culture to gain market" concept. 


\section{Summary}

Due to the rapid development of the productive forces, people's aesthetic view also gradually changed, and began to pursue the stay of personalized style. Book foothold in the fierce market, advancing with The Times, and should focus on the reader, to be set for a specific consumer crowd. As designed for the integrated design books on value-added effect, can satisfy the reading psychology of people easily, high efficiency, make the better help readers grasp and experience the feeling of happiness and life. In terms of sales, the best-selling books or not, in addition to the content contained in the spirit of the meet a certain role, books integrated design plays an important role, it is opened the book aroused people's psychological motivation, transmitting the aesthetic characteristics of an era and the development of economic information, the performance characteristics of the book content, make the reader willing to buy.

\section{Acknowledgement}

Youth Fund Project of the Research on Humanities and Social Sciences of the Ministry of Education in 2014(No.14YJC760080).

\section{References}

[1] X.G. Hao, Product packaging in the role of marketing. Journal articles 2014, 2014, vol.6, pp.9 -11.

[2] J.X. Shao, The analysis of information process consumer impulse buying behavior, Journal of education, 2012, vol.5, pp.28-32.

[3] J.Zh. Liu, The paper discusses of the evolution in the ancient books integrated design, Features of the library in the new century, 2006, vol.3, pp.13-17.

[4] X.J. Ding, Theory of Chinese books in the design of the importance of aesthetic connotation, Inner Mongolia normal university, 2008, vol.2, pp.18-11.

[5] H.Y. Shang, Books integrated design, 2011 journal articles and technology, 2013, vol.3, pp.8-11.

[6] G.T. Chen, Modern society and the guide mechanism of the relationship between income and consumption, Research public BBS 2010, 2010, vol.7, pp.34-37.

[7] H.T. Huang, A special commodity of special packaging: books, Journal articles in the integrated design of 2006, 2015, vol.9, pp.55-58. 